\title{
As novas formas organizacionais do setor atacadista distribuidor e a logística no território brasileiro
}

\author{
Marcos Xavier* \\ Ricardo Castillo**
}

\section{Resumo}

A eficácia dos fluxos das cadeias de suprimento torna-se central ao aprofundamento da divisão territorial do trabalho e às novas formas de consumo. Como resultados territoriais desta situação, destacam-se a implantação ou modernização de infraestruturas, as novas topologias e sistemas organizacionais das empresas, as normas técnicas e institucionais correlatas e as novas especializações produtivas de lugares e regiões. Nessa situação, a logística funciona como um catalisador dos fluxos de produção que viabilizam o aprofundamento da divisão territorial do trabalho e tende a ser um atributo de certos subespaços do território, correspondendo à especialização produtiva de lugares selecionados que viabilizam a fluidez da circulação e distribuição de bens. Nesse contexto, o setor atacadista distribuidor estabelece um elo entre a produção e o pequeno varejo, interferindo no arranjo logístico do território brasileiro diante do imperativo da competitividade.

Palavras-chave: Logística; Atacadista distribuidor; Arranjos produtivos territoriais; Pequeno varejo.

\footnotetext{
* Universidade Federal da Integração Latino Americana - UNILA (marcos.xavier@unila.edu.br).

** Instituto de Geociências da UNICAMP (castillo@ige.unicamp.br)
}

Geosul, Florianópolis, v. 25, n. 50, p 39-58, jul./dez. 2010 
XAVIER, M. \& CASTILLO, R. As novas formas organizacionais do setor...

The new organization of the wholesale distribution sector and the logistics in Brazilian territory

\begin{abstract}
The current space division of labour increases the importance of circulation in production process and imposes a rapid and more frequent replacement of supplies, according to shorter stated periods, both in industry and retail. In Brazil, the opening of the economy, imposing a bigger competitiveness to the companies, and the social and territorial expansion of consumption have affected the organization and the structure of the wholesale companies. In reply, the logistics, as the management of the flow of goods, information and other resources, has enhanced the activities of planning and control. As the logistics becomes more important, a new organization of territory arises, increasing the relationships among places. Thus, we conclude that the wholesale distributors continue exerting a significant role in the intermediation between the industry and small retail. The modernization of Brazilian wholesale companies play an important role in the new spatial arrangement of the circuits of production and in the relationships among cities, which contributes to the short circuit of the urban and regional networks and confirm the link existing between the two circuits of urban economy in Brazil.
\end{abstract}

Key words: Logistics; Wholesale distributor; Clusters; Small retail.

\title{
Introdução
}

A abertura da economia brasileira nos anos noventa levou à formação de um acirrado ambiente competitivo entre as empresas, mas também entre os subespaços do território nacional que, mediante a reformulação do papel do Estado, viram-se induzidos a buscar respostas individuais em relação à geração de um desenvolvimento econômico próprio, mediante a ausência de um 
XAVIER, M. \& CASTILLO, R. As novas formas organizacionais do setor...

projeto nacional. Concomitantemente, a busca por estratégias que reduzissem custos operacionais e agregassem valor aos produtos conduziram a logística a ser um elemento imprescindível ao planejamento estratégico das empresas, sobretudo na manutenção e crescimento de seus mercados. Esta situação acabou por conduzir as diversas escalas do poder público, União, estados e municípios, a priorizarem em seus projetos e ações a criação de objetos e normas que viabilizassem uma maior eficácia dos circuitos espaciais de produção, tendendo a criar uma configuração territorial que permitisse uma maior fluidez da distribuição física dos bens.

Em meio a esta situação, tem ocorrido uma verdadeira ebulição no setor logístico. Surgem cursos profissionalizantes, linhas de pesquisa, publicações especializadas, associações setoriais e empresas envolvidas nas múltiplas etapas do processo logístico, desde o planejamento, estocagem, burocracia e distribuição até o consumidor final. Neste contexto, as empresas atacadistas distribuidoras redefinem suas estratégias e funções a fim de sobreviverem às novas formas de organização das indústrias e do comércio varejista.

\section{A logística como conteúdo do território}

De forma geral, a logística constitui-se como um conjunto de atividades técnico-organizacionais que tem por finalidade garantir a distribuição de bens como matéria prima, semi-elaborados, peças e produtos acabados de forma eficaz, o que inclui cumprimento de prazos e manutenção da integridade do bem a ser distribuído. Segundo Novaes $(2001,35)$,

para o Council of Logistics Managment norte-americano, a logística é o processo de planejar, implementar e controlar de maneira eficiente o fluxo e a armazenagem de produtos, bem como os serviços e informações associados, cobrindo desde o ponto de origem até o ponto de consumo, com o objetivo de atender aos requisitos do consumidor. 
XAVIER, M. \& CASTILLO, R. As novas formas organizacionais do setor...

A partir do conceito de espaço geográfico como um conjunto indissociável de sistemas de objetos e sistema de ações, proposto por Santos $(1996,51)$, podemos considerar a logística como um subsistema e uma variável chave para a compreensão da atual dinâmica territorial brasileira. Podemos então definir a logística como um conjunto de competências infra-estruturais, normativas e operacionais, colocadas a serviço da organização dos fluxos e da racionalidade da circulação, garantindo fluidez aos circuitos espaciais produtivos e aos agentes e lugares que deles fazem parte.

Como observa Fleury $(2000,28)$, em decorrência da globalização, aumentam o número de clientes e os pontos de vendas, crescem o número de fornecedores e os locais de fornecimento, aumentam as distâncias a serem percorridas e a complexidade operacional, envolvendo legislação, cultura e modais de transporte. Também aumentam a quantidade de insumos e a complexidade no planejamento e controle da produção e dos estoques, além de uma maior dificuldade de previsão de vendas, tornando a logística mais complexa. Mas ela também corresponde ao atual front de racionalização e redução de custos para garantir a competitividade das empresas e manter ou conquistar mercados. A logística torna-se então estratégica e emerge como uma atividade de natureza técnico-científica e informacional, que passa a agregar valor aos bens ao longo dos circuitos espaciais produtivos nas mais diversas cadeias de distribuição.

Tratá-la como um conteúdo do território a partir de uma base conceitual em que objetos e ações são indissociáveis permite compreendê-la como um arranjo sistêmico de objetos técnicos, normas e ações que acaba por agregar valor também aos lugares e regiões onde se apresenta de forma mais densa e eficaz. Como nota Monié (2001, p.10), “a logística envolve não apenas a fluidez das circulações dada pelos transportes, mas também as relações entre estes e os serviços de apoio ao comércio e à produção que agregam valor ao fluxo". Como este mesmo autor observa (id., p.21), a logística não consiste na mera articulação entre infra-estruturas e recursos técnicos que garantem a fluidez da circulação de bens, 
XAVIER, M. \& CASTILLO, R. As novas formas organizacionais do setor...

mas pressupõe um arranjo técnico-institucional que mobiliza recursos econômicos, sociais, políticos e culturais localizados, a serviço das redes materiais e imateriais que qualificam a competitividade das regiões.

Como assevera Santos (1996, p.185),

um processo produtivo tecnicamente fragmentado e geograficamente espalhado exige uma permanente reunificação para ser eficaz. O aprofundamento resultante da divisão territorial do trabalho impõe formas novas e mais elaboradas de cooperação e de controle. As novas necessidades de complementaridade surgem paralelamente à necessidade de vigiá-las, acompanhá-las e regulá-las.

Os operadores logísticos ${ }^{1}$ emergem como resultado desta nova situação em que a circulação eficaz torna-se imperativa para a competitividade da indústria e do varejo. Nesse sentido, as grandes empresas atacadistas distribuidoras têm deixado de ser meras revendedoras de produtos industrializados, passando também a prestar serviços de planejamento e gestão em matéria de marketing, visando garantir e ampliar um nicho de atuação também como operadores logísticos.

A modernização das grandes empresas atacadistas brasileiras sinaliza para uma redefinição do setor, que tende a assumir um papel mais ativo, redefinindo sua função de elo entre os dois circuitos espaciais da economia (Santos, 1979) ao se constituir como um canal de comunicação entre a indústria e o pequeno varejo moderno e tradicional, incluindo inúmeras formas de comércio popular de rua que se proliferam nas cidades brasileiras

${ }^{1}$ Segundo a Associação Brasileira de Movimentação e Logística - ABML (1999), o operador logístico "é o fornecedor de serviços logísticos especializado em gerenciar todas as atividades de logística ou parte delas, nas várias fases da cadeia de abastecimento de seus clientes, agregando valor ao produto dos mesmos e que tenha competência para, no mínimo, prestar simultaneamente serviços nas três atividades básicas: controle de estoques, armazenagem e gestão". 
XAVIER, M. \& CASTILLO, R. As novas formas organizacionais do setor...

em função da expansão do circuito inferior da produção, decorrente da inserção competitiva do país na economia internacional.

\section{A intermediação entre os circuitos das empresas}

Cada circuito espacial da produção, isto é, as diversas etapas pelas quais passam os produtos desde o começo do processo de produção até chegar ao consumo final (Santos, 1988) e as respostas e o comportamento dos lugares que abrigam essas etapas, promove uma vida de relações própria que contribui para definir alguns conteúdos da dinâmica do território, como o abastecimento de insumos e produtos, a oferta de serviços na esfera política, econômica, social e cultural, os fluxos de diferentes naturezas e a criação das normas necessárias à produção.

Como observa Xavier $(2002,14)$, cada empresa, segundo o ramo de atividade, grau de capitalização e nível técnico e de organização, ativa pontos e áreas que constituem a base material de sua existência, como dados da produção, da circulação e do consumo que se manifestam geograficamente. Tais pontos e áreas, que correspondem à sua topologia, manifestam a divisão territorial do trabalho particular de cada empresa e, desta maneira, as suas lógicas territoriais. A distribuição no território dos pontos de interesse para operação das empresas, associada aos circuitos espaciais da produção, oferece uma visão do movimento do território, demonstrando como os fluxos o perpassam e como se dá seu uso privativo.

Os mercados oferecem uma visão da escala dos resultados de cada empresa e podem ser considerados como uma medida de sua força, pois, no atual período, a capacidade de circulação tornou-se um dado central do processo produtivo. O território e o mercado se realizam como lugares geográficos e políticoeconômicos da concorrência entre as empresas (SANTOS, 1999) e as extensões e geometrias desses mercados constituem parte central do jogo competitivo entre elas. 
XAVIER, M. \& CASTILLO, R. As novas formas organizacionais do setor...

Como as empresas possuem capacidades diferenciadas de rentabilizar o uso do território em seus respectivos circuitos, a capacidade de intervir na dinâmica territorial é desigual. $O$ território abriga, portanto, uma dialética entre diversas divisões particulares do trabalho que disputam seu uso (SANTOS \& SILVEIRA, 2001, p.290) e que, sobrepostas, compreendem a totalidade da situação geográfica de cada lugar e da respectiva formação sócio-espacial.

Tomando o caso brasileiro, devemos considerar que os circuitos das firmas (SANTOS, 1986) são parte constitutiva dos circuitos espaciais da economia que incluem a distribuição e o consumo de bens e serviços. Segundo Santos (1999), as empresas funcionariam segundo três circuitos espaciais da produção: o macro, o meso e o micro-circuito.

$\mathrm{O}$ macro-circuito corresponderia àquele que se realiza através dos pontos mais modernos do território, cujo alcance corresponde simultaneamente ao mercado nacional e internacional. Trata-se do circuito espacial das empresas globais, nacionais ou estrangeiras, capazes de criar consumo através da publicidade. São empresas sequiosas de fluidez que interferem na política do Estado a fim de influenciar a instalação dos modernos sistemas técnicos e normas que possibilitam a eficácia e rentabilidade de suas ações.

$\mathrm{O}$ meso-circuito estaria restrito às fronteiras do país ou a uma ou mais regiões. Trata-se de uma tipologia bastante extensa de empresas com um nível de operação inferior ao das empresas globais devido às suas dimensões técnicas, econômicas e políticas. As empresas desse circuito são mais dependentes das demandas do mercado interno e tendem a imitar os produtos do macro-circuito, valendo-se de sua propaganda.

As empresas de pequeno porte correspondem ao microcircuito. São aquelas empresas cujo consumo induz a produção. Trata-se de empresas cuja capacidade de sobrevivência advém da flexibilidade que possuem de se adaptar às contingências do próprio meio ambiente construído. São pouco capitalizadas, valendo-se do trabalho intensivo que as torna responsáveis por 
XAVIER, M. \& CASTILLO, R. As novas formas organizacionais do setor...

importante parcela de postos de trabalho para a população que não participa das atividades mais modernas.

As empresas do macro-circuito possuem grande capacidade de modificar a escolha dos lugares em que desejam operar e utilizam essa agilidade para chantagear ${ }^{2}$ lugares e territórios. Já as empresas do micro-circuito e parcela das empresas do mesocircuito são geograficamente mais fixas. Segundo Xavier (2002, 18), são empresas cuja condição de permanência é mais dependente das condições de uso da parcela do território em que se instalam, seja em relação às condições de produção, seja em relação ao mercado. Isto se dá devido à sua menor capacidade de mobilidade espacial e por terem mercados totalmente, ou em grande parte, locais e regionais. Deste maior vínculo com o território advém a necessidade de ser mais flexível, adequando-se, com certa rapidez, às modificações do consumo em relação à freqüência, aos tipos de produtos e à quantidade adquirida em cada compra, além de formas de crédito baseadas em relações de confiança como a "venda a fiado" ou "caderneta de compra".

Ao analisar os circuitos espaciais da economia urbana na década de 1970, Santos (1979) observou que

os habitantes dos bairros pobres compravam no local, pois o preço dos transportes não lhes permitia ter acesso ao comércio moderno, freqüentemente situado no centro das cidades ou nos seus arredores. A densidade e a distribuição das lojas estariam, desta maneira, calcadas nas possibilidades de deslocamento a pé da clientela. A dimensão dos comércios era uma adaptação a um consumo pequeno e irregular (p.168).

2 Esta chantagem refere-se às formas de pressão das grandes empresas sobre Estados e municípios, exigindo condições para sua instalação ou permanência, envolvendo ações dirigidas à dotação e/ou modernização das infra-estruturas, além da criação de normas características de uma solidariedade institucional. Como exemplo, temos a guerra fiscal entre os Estados brasileiros a fim de atrair novos investimentos. Ver Castillo et al. (1997). 
XAVIER, M. \& CASTILLO, R. As novas formas organizacionais do setor...

A necessidade do pequeno comerciante de se reabastecer de produtos diversificados, em pequena quantidade, todos os dias, colocava-o na dependência do atacadista, criando uma relação de intermediação na cadeia de distribuição. Segundo este mesmo autor (1979, p.186), o atacadista seria o elo entre os circuitos superior e inferior da economia por ter acesso ao crédito bancário e financiar os varejistas com dinheiro e na forma de mercadorias faturadas. A flexibilidade e a sazonalidade característica do circuito inferior da economia encontrariam nos atacadistas uma forma de crédito que não exigiria a racionalidade, as garantias e o cumprimento de prazos próprios dos bancos. A demanda por um abastecimento irregular e de volume reduzido no varejo de bairro, como já observado, não é um dado novo. As novas formas organizacionais no varejo e no atacado geradas pela transformação da economia brasileira diante da globalização certamente trazem novas indagações acerca do papel dos atacadistas como elo entre os diferentes circuitos espaciais da produção e como viabilizadores do comércio popular que se expande no Brasil.

\section{Os atacadistas distribuidores na cadeia de suprimentos: os desafios diante das transformações da produção e do varejo}

Segundo Novaes (id., p.38), "o longo caminho que se estende desde as fontes de matéria-prima, passando pelas fábricas dos componentes, pela manufatura do produto, pelos distribuidores, e chegando finalmente ao consumidor através do varejista, constitui a cadeia de suprimento". Como as cadeias de suprimento são cada vez mais complexas, envolvendo inúmeras atividades complementares e geograficamente dispersas, elas acabam, graças ao aprofundamento da divisão territorial do trabalho, por corresponder a diversos circuitos espaçais produtivos nos quais são estabelecidos múltiplos fluxos de mercadorias e informação entre os subespaços do território.

Estas cadeias podem assumir diferentes feições conforme o produto, o mercado e o nível de capital e tecnologia envolvidos. 
XAVIER, M. \& CASTILLO, R. As novas formas organizacionais do setor...

Formam-se desta maneira diferentes canais de distribuição definidos, conforme Fleury (id., p.40), como "o conjunto de unidades organizacionais, instituições e agentes, internos e externos, que executam as funções que dão apoio ao marketing de produtos e serviços de determinada empresa". Estas funções incluem compra, venda, informação, transporte, armazenagem, estoque, programação da produção e financiamento. No seio desta complexa rede de relações, encontram-se os atacadistas distribuidores como um elo entre as indústrias e o pequeno varejo, que tem ganhado expressão no Brasil.

Segundo estudo realizado pela Fundação Getúlio Vargas (2003), o comércio varejista tem passado por uma série de mudanças, dentre as quais se destaca o crescimento do número de supermercados independentes e do varejo tradicional ${ }^{3}$. Transformações significativas em termos organizacionais e estruturais deste setor, envolvendo particularmente a logística de distribuição ${ }^{4}$, são acompanhadas por uma nova feição do comércio de vizinhança, que passa a incluir, além das associações cooperativas de pequenos supermercados, os grandes grupos empresariais sob a forma de bandeiras populares como Dia $\%$ e Econ $^{5}$.

3 Supermercados independentes correspondem àqueles que possuem um único equipamento de varejo (apenas uma loja) e o varejo tradicional, àquele em que o atendimento depende de vendedores e balconistas, em geral, associado ao comércio de pequenas proporções como lojas de roupas, calçados, quitandas, padarias e farmácias, entre outros.

${ }^{4}$ A atividade logística abrange toda a cadeia de suprimentos que, "corresponde ao caminho percorrido durante a fabricação de um bem, desde o fornecimento de matéria prima, passando pelas fábricas dos componentes, pela manufatura do produto, pelos distribuidores, e chagando finalmente ao consumidor final através do varejista" (NOVAES, 2001, p.38). Para os fins deste artigo será tratada, em particular, a logística associada à distribuição do produto acabado para o consumo final.

5 "O Econ segue o mesmo conceito de negócio da bandeira Dia\%, do Carrefour, conhecido como hard discount. Neste formato, as lojas são pequenas, entre 300 a 400 metros quadrados, de baixo custo operacional e com foco em ofertas. A 
XAVIER, M. \& CASTILLO, R. As novas formas organizacionais do setor...

As transformações no consumo, com a maior freqüência das compras de pouca quantidade no pequeno varejo associada à busca pelo menor preço, têm imposto uma nova organização logística (RAMOS, 2002; CAMPOS, 2003; PENNACCHI, 2004; GONÇALVES, 2004). Diante da necessidade de repor pequenos estoques com maior freqüência, a melhoria desta organização passa a ser imperativa para o ganho de competitividade, tanto para a indústria, quanto para o varejo (HIJAR et al., 2006). A estes fatos, soma-se a característica deste varejo de pequenas proporções de atender à demanda de necessidades básicas do consumidor, estando normalmente estabelecido próximo ao local de moradia, o que implica maior dispersão no território nacional. Como resultado, o varejo tende a aumentar suas exigências em relação às entregas e à precisão no cumprimento dos prazos e a indústria busca adaptar seus sistemas de distribuição aos parâmetros do mercado.

Conforme pesquisa ABAD (Associação Brasileira de Atacadistas e Distribuidores de Produtos Industrializados) e Latin Panel, 53\% do pequeno varejo brasileiro (de um a quatro check outs), formado, sobretudo, por mercearias e pequenos supermercados (Revista Distribuição, ano XIV, $\mathrm{n}^{\circ}$ 164. setembro de 2006 ), obtém de $66 \%$ a $90 \%$ de seu mix de produtos no atacado distribuidor.

Por outro lado, as indústrias são desafiadas a atender este pequeno varejo e, assim, também esperam uma ação dos atacadistas distribuidores que viabilize as compras territorialmente dispersas, mais freqüentes e em menores quantidades, exigidas por ele. Para Nunes (2001, p.12), “a indústria busca distribuidores que possam agregar valor e serviços que ela ainda não consiga viabilizar com seus próprios recursos e estrutura".

Neste novo contexto, a atividade atacadista tende a se reformular para atender às exigências do pequeno varejo. Conforme Ramos (2002), o atacadista tende a se tornar um

idéia é disputar o mercado dos pequenos comerciantes, supermercados, mercearias e quitandas, em bairros de periferia." (Valor Econômico, 12/05/03) 
XAVIER, M. \& CASTILLO, R. As novas formas organizacionais do setor... prestador de serviços, um operador logístico ${ }^{6}$. Além de uma distribuição mais eficaz em termos de custo, volume e tempo, ele passa a prestar serviços de suporte, de definição de estratégias e de qualificação do pequeno comerciante varejista. Segundo a ABAD, $17 \%$ das empresas atacadistas associadas também atuam como

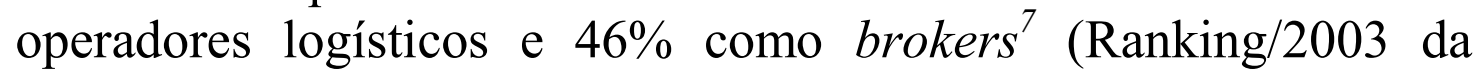
ABAD).

O setor atacadista é o principal canal de abastecimento do pequeno varejo e este, por sua vez, apresenta-se como o principal canal de acesso ao consumo da população de baixa renda, situada nos grandes centros urbanos ou nas regiões onde não há interesse por parte das grandes empresas do setor $^{8}$. Desta maneira, as empresas atacadistas são de suma importância para o processo de distribuição, particularmente de bens associados ao consumo de produtos de alimentação, bebida, higiene e limpeza, que juntos corresponderam, em 2005, a 66,2\% do total de vendas realizadas pelas empresas atacadistas vinculadas à ABAD.

${ }^{6}$ Segundo Trevisan (2004, p.45) "as atividades destes operadores compreendem procedimentos desde a produção, armazenagem até a distribuição final de produtos e fluxos materiais e imateriais". Desta forma, o atacadista tende a não existir mais para comprar e vender mercadoria, mas sim, para ser um prestador de serviços como nota Ramos (2004). Segundo este mesmo autor, "ele tem que garantir que esses produtos estejam lá na ponta, a preços competitivos, com qualidade, no dia certo, para atender o ciclo quase diário de reposição".

7 Correspondem a empresas especialmente contratadas pelas indústrias para atender às lojas independentes. Seu objetivo é aproximar as indústrias dos estabelecimentos até 10 check outs (caixas), tornando-os mais competitivos devido ao menor preço de aquisição dos produtos. Neste sistema, a loja não mantém estoque próprio e a nota fiscal é emitida diretamente em nome da indústria e não em nome do Broker, o que reduz a incidência de taxas como Cofins, CPMF e PIS (Revista Supermercado Moderno, Dez.,2000).

${ }^{8}$ Segundo Pesquisa sobre Micro e Pequenas Empresas comerciais e de serviços no Brasil (IBGE, 2003, p.26), "o pequeno comércio ainda tem uma presença marcante nas cidades do interior e nas localidades de baixa renda, além de representarem uma opção rápida e barata para o atendimento das necessidades básicas dos consumidores". 
XAVIER, M. \& CASTILLO, R. As novas formas organizacionais do setor...

Segundo esta mesma Associação, com base em dados da AC Nielsen, graças ao bom desempenho do pequeno varejo, que corresponde a $39 \%$ do mercado de consumo, o setor atacadista distribuidor faturou, em 2004, $\mathrm{R} \$ 76,5$ bilhões, representando $55,4 \%$ do mercado de abastecimento brasileiro e tendo apresentado um crescimento de $11,9 \%$ em relação a 2003. Entre as modalidades das empresas do setor encontramos: 1) as de atendimento no balcão, 2) as de auto-serviço, que de forma semelhante ao comércio varejista, possui lojas com produtos dispostos nas gôndolas sem necessitar de balconistas ou vendedores e 3) as de entrega, que correspondem aos atacadistas distribuidores que, a partir de seus centros de distribuição, atendem a inúmeros pontos de venda do varejo segundo operações realizadas à distância via telefone, sistema informatizado ou através de vendedores que visitam estes pontos.

É importante notar, porém, que as associações formadas pelos pequenos supermercados podem adotar formas racionais de organização que os tornem menos dependentes do atacadista através das centrais de compras. Destarte, os atacadistas encontram nestas associações um canal de distribuição rival que coloca os pequenos varejistas em contato direto com os fornecedores. Frente a esta situação, as grandes empresas atacadistas também passam a constituir suas próprias associações. O grupo Martins e o grupo Peixoto, empresas que estão entre os maiores atacadistas do país, ambas com sede em Uberlândia, Minas Gerais, criaram centrais de negócios que reúnem pequenos varejistas sob uma mesma bandeira de loja (Smart / Martins, com 634 lojas em 9 estados brasileiros e Rede Valor / Peixoto, com 240 lojas nos estados de São Paulo, Minas Gerais e Paraná), oferecendo melhores condições de negociação, padronização de pontos-de-venda e presença na mídia. Mesmo empresas de menor porte como a Spani Atacadista, que atua apenas em parte da região sudeste brasileira, utilizam mecanismos de fidelização para permanecer no mercado. Esta empresa oferece aos pequenos varejistas associados um maior prazo de pagamento, descontos, lay out, treinamento, entrega mais 
XAVIER, M. \& CASTILLO, R. As novas formas organizacionais do setor...

rápida, jornal de ofertas, mix de produtos diferenciado e maior freqüência de visitas de seus representantes (Revista Distribuição, ano XIV, $\mathrm{n}^{\mathrm{o}}$ 163, agosto de 2006). Desta maneira, estabelecem novas relações com o pequeno varejo e novas formas de organização da logística de distribuição, visando uma fidelização que impeça uma mudança no canal de distribuição no sentido de dispensar a existência do atacadista distribuidor, já que as centrais teriam condições de serem abastecidas diretamente pelas indústrias.

A propagação de pequenos mercados de bairro nos grandes centros urbanos controlados pelas empresas do macro-circuito (como as mencionadas redes Dia\%, do Carrefour e Econ, da CBA) também traz novos desafios, tanto aos atacadistas, quanto ao varejo mercearil do micro-circuito. Concorrentes diretos, presentes nas áreas de alta densidade de população de baixa renda, particularmente nos bairros periféricos, estas redes desafiam o pequeno varejo independente a melhorar $o$ atendimento, diversificar os produtos oferecidos e a reduzir os preços, o que leva à necessidade de uma reformulação do setor atacadista que também se vê pressionado por esta concorrência.

Grandes empresas como o Martins passam a utilizar inovações logísticas para agregar valor aos clientes e garantir sua permanência no mercado distribuidor. Como observa Fleury (2000, p. 33),

apesar de formalmente classificado como atacadista, o Martins pode ser visto como um prestador de serviços logísticos para o pequeno varejista, oferecendo entrega rápida de uma ampla variedade de produtos, que podem ser adquiridos de forma fracionada, em pequenas quantidades, com financiamento garantido e assistência técnica. Ao oferecer esse pacote de serviços, o Martins gera enorme valor para o pequeno varejista que por não dispor de capital de giro, enfrenta enormes dificuldades para garantir disponibilidade de um sortimento adequado de produtos. Dessa maneira o Martins não só contribui para a 
XAVIER, M. \& CASTILLO, R. As novas formas organizacionais do setor...

viabilização do pequeno varejo, mas cria para si próprio um mercado mais sólido e próspero.

A reestruturação da atividade atacadista distribuidora, sobretudo nas duas últimas décadas, além de redefinir os vínculos entre os diferentes circuitos de firmas no seio das cadeias de suprimentos, também acompanha a produção de novos arranjos territoriais que tendem, por um lado, a organizar lugares e regiões em função desta atividade e, por outro, a redefinir as redes e fluxos no território nacional e, portanto, as relações entre lugares e regiões.

\section{As empresas atacadistas e as novas especializações logísticas do território}

A atividade atacadista viabiliza uma distribuição territorialmente estendida e mais capilar por atingir inúmeros pequenos pontos de venda varejista. Em função de um sistema de distribuição mais eficaz dos bens industriais, subespaços do território brasileiro têm conhecido um novo conteúdo de especialização, calcado na atividade distribuidora.

Como a logística inclui formas técnicas materiais $\mathrm{e}$ imateriais e formas organizacionais, estabelecendo sistemas territorializados, há uma relação entre a localização dos centros de distribuição das empresas atacadistas distribuidoras com os novos arranjos territoriais vinculados à criação de pólos logísticos, centros logísticos integrados ou plataformas logísticas. Esses novos conceitos que têm direcionado políticas públicas no âmbito municipal, estadual e federal a fim de ampliar a fluidez do território, criando, como observa Cataia (2003, p. 404), uma verdadeira "ortopedia territorial" adequada às empresas, que onera os cofres públicos para adaptar o território aos interesses privados que, por vezes, são efêmeros e desvinculados das necessidades locais.

Uberlândia (MG) tem se destacado como um pólo atacadista distribuidor de âmbito nacional. Segundo ranking ABAD, em 2005 
XAVIER, M. \& CASTILLO, R. As novas formas organizacionais do setor...

Uberlândia era sede de seis dos 10 maiores atacadistas distribuidores do país, destacando-se o Martins, a ARCOM e a Megaforte, ocupando as três primeiras posições do ranking. Segundo Bessa e Soares (2003, 27), "após a década de 1970, a cidade presenciou mudanças importantes no setor terciário, especialmente associadas às práticas dos atacado-distribuidores que, de 90 empresas instaladas em 1970, chegam a 642 em 1990". Como estas autoras observam (idem, 22),

a consolidação de um entroncamento aéreo-rodoviário em Uberlândia garante a circulação material - objetos e mercadorias - e também o intercâmbio de pessoas com os principais aeroportos, portos e cidades do país, demonstrando uma reconfiguração dos pontos interligados em decorrência das novas interações mantidas por essa cidade, cuja racionalidade incrementa fluxos que ultrapassam os limites regionais e atingem o contexto nacional, a fim de atender, primordialmente, às exigências dos estabelecimentos agronidustriais e dos atacadodistribuidores.

Anápolis (GO), situada entre Goiânia e o Distrito Federal, é outro exemplo de especialização produtiva voltada à logística de distribuição de produtos industrializados. Segundo Hajjar (Revista Economia e Desenvolvimento, outubro/dezembro de 2004),

o município de Anápolis tem tradição de entreposto comercial e possui forte segmento atacadista distribuidor com mais de 80 empresas que distribuem mercadorias para os estados de São Paulo, Minas Gerais, Bahia, Mato Grosso, Tocantins, Goiás, Maranhão e Sul do Pará, cobrindo grande parte das regiões brasileiras. O município também apresenta um projeto em execução de construção de uma plataforma logística que integrará, no mesmo local, inteligência logística e prestação de serviços na recepção e distribuição de mercadorias e que, entre outros equipamentos, disponibilizará um centro de carga 
XAVIER, M. \& CASTILLO, R. As novas formas organizacionais do setor...

rodoviária dedicado aos operadores logísticos, empresas de transportes e redes atacadistas e varejistas.

Outros novos pólos tendem a se formar a partir de ações conjuntas do poder público, associações setoriais e empresas privadas (Revista Distribuição, ano XIV, n. 163, agosto de 2006). São exemplos o Pólo Atacadista Industrial de Taquaralto em Palmas (TO), o projeto para o Pólo Atacadista de Maracanaú, próximo à Região Metropolitana de Fortaleza (CE), além de projetos situados nos estados do Maranhão e do Piauí.

\section{Considerações finais}

Diante da reestruturação produtiva do território associada à expansão do meio técnico-científico-informacional e a inserção competitiva do Brasil na globalização, a logística tornou-se um setor da economia estratégico para a competitividade das empresas diante da maior disputa por mercados e pela pressão para maior eficácia da cadeia produtiva e de distribuição.

No seio deste processo, tem ocorrido uma pressão por parte da indústria e do comércio varejista para tornar os canais de distribuição de bens industriais mais racionais, oferecendo entregas rápidas, com reposição freqüente de pequenos volumes em diversos pontos de venda, com mix de produtos variados e ao menor custo. A necessidade de a indústria assumir maior controle sobre seus fluxos produtivos e, portanto, sobre suas vendas, obtendo informações sobre o consumidor final, a força adquirida pelos grandes grupos de supermercados capazes de se abastecerem diretamente na indústria e as centrais de negócios de pequenos e médios varejistas que se organizam para obter melhores preços de seus fornecedores, têm obrigado as empresas atacadistas distribuidoras a investir na inovação tecnológica e organizacional, tendendo a mudar seu papel no elo da cadeia de suprimentos, passando da simples compra do setor industrial e revenda para o pequeno e médio varejo para um prestador de serviços e 
XAVIER, M. \& CASTILLO, R. As novas formas organizacionais do setor...

controlador de centrais de negócios, garantindo a intermediação entre as empresas do macro, meso e micro circuitos.

Como resultado territorial da maior importância da fluidez no seio do processo produtivo, tem-se a formação de um novo arranjo logístico territorial que se desenha através dos novos fixos, como centros de distribuição e novos fluxos mais diversificados, freqüentes e territorialmente estendidos, dos quais fazem parte diversos operadores logísticos e as modernas empresas do setor atacadista-distribuidor. Esses fixos e fluxos tendem a redefinir especializações geográficas e a vida de relações entre os lugares, assim como a maior ou menor acessibilidade da população aos bens industriais de primeira necessidade, comercializados no varejo mercearil.

\section{Referências bibliográficas}

BESSA, K.; SOARES, B. Novas espacialidades urbano-reguonais perante a expansão do meio técnico-científico-informacional: o exemplo de Uberlândia. Mercator, ano 02, n. 04, p. 19-34, 2003.

CAMPOS, V. Toda a força aos pequenos. Disponível em: Www.revistadistribuicao.com.br (2003). Acesso em junho de 2008.

CASTILLO, R.; TOLEDO JUNIOR, R.; ANDRADE, J. Três dimensões da solidariedade em Geografia. Experimental, n. 3, p. 69-99, 1997.

CATAIA, M. Alienação do território: papel da guerra fiscal no uso, organização e regulação do território brasileiro. In SOUZA, M. A. (org.) Território brasileiro, usos e abusos. Campinas: Territorial, 2003.

FLEURY, P.; WANKE, P.; FIGUEIREDO, K. F. (org.) Logística empresarial: perspectiva brasileira. São Paulo: Atlas, 2000. 
XAVIER, M. \& CASTILLO, R. As novas formas organizacionais do setor... $\overline{\text { FUNDAÇÃO GETÚLIO VARGAS - EAESP (2003). Impactos }}$ verticais da concentração do setor varejista brasileiro. Disponível em: www.fgv.com.br. Acesso em junho de 2008.

GONÇALVES, J. O dilema das líderes. Disponível em: www.revstadistribuicao.com.br (2004). Acesso em junho de 2008.

HIJAR, M. et al. Evolução do desempenho logístico das indústrias de bens de consumo: uma análise sob a perspectiva do varejista. Disponível em: www.centrodelogisticacom.br/. Acesso em setembro de 2006.

FUNDAÇÃO IBGE. As micro e pequenas empresas comerciais e de serviços no Brasil em 2001. Rio de Janeiro: IBGE, 2003.

MONIÉ, F. Logística de transporte, modernização portuária e inserção competitiva do Rio de Janeiro na economia global. Território, n. 10, jan/jun. 2001.

NOVAES, A C. Logística e gerenciamento da cadeia de distribuição: estratégia, operação e avaliação, Rio de Janeiro: Campos, 2001.

NUNES, M.N. Quem vai distribuir?, Projeções e estratégias sobre $3 \mathbf{P}$ do marketing para empresas intermediárias no Brasil. Rio de Janeiro: Qualitymark, 2001.

PENNACCHI, P.H. O outro lado do Brasil. Distribuição, 2004.

RAMOS, C. O setor atacadista Disponível em: www.revistanegocios.com.br (2002). Acesso em junho de 2008.

SANTOS, M. O espaço dividido: os dois circuitos da economia urbana dos países subdesenolvidos. Rio de Janeiro: Francisco Alves, 1979. 
XAVIER, M. \& CASTILLO, R. As novas formas organizacionais do setor...

SANTOS, M. Circuitos espaciais da produção: um comentário. In: SOUZA, M. A. A.; SANTOS, M. (org.). A construção do espaço. São Paulo: Nobel, 1986.

SANTOS, M. Metamordoses do espaço habitado. São Paulo: Hucitec, 1988.

SANTOS, M. A natureza do Espaço: técnica e tempo, razão e emoção. São Paulo: Hucitec, 1996.

SANTOS, M. Empresas Territoriais e dinâmicas da formação socioespacial brasileira. Projeto de pesquisa, mimeo. 1999.

SANTOS, M. \& SILVEIRA, M. L. O Brasil: território e sociedade no início do século XXI. Rio de Janeiro: Record, 2001.

TREVISAN, L. Logística, informação e reorganização do território brasileiro: nova racionalidade e controle dos fluxos materiais e imateriais. Monografia de conclusão de curso (Bacharel em Geografia). Instituto de Geociências da Universidade Estadual de Campinas. Campinas, 2004.

XAVIER, M. A. M. As empresas e o uso do território brasileiro. Acidade de São José do Rio Preto vista através da dinâmica territorial de suas empresas (Mestrado em Geografia). Universidade de São Paulo. São Paulo, 2002.

Recebido em novembro de 2009

Aceito em setembro de 2010 